\title{
Analysis of the Status Quo of Humanistic Quality-oriented Education in Medical Colleges and Universities
}

\author{
Shulei Liu \\ Dermatological Department, 324 Hospital of Chinese People's Liberation Army \\ Chongqing 400020, China \\ E-mail: bbscnn@yahoo.cn \\ Yamin Li \\ Business Administration Department, Chongqing Education College \\ Chongqing 400067, China \\ E-mail: xiaomin50@126.com
}

Received: July 15, 2011 Accepted: August 9, $2011 \quad$ Published: February 1, 2012

doi:10.5539/ies.v5n1p216

URL: http://dx.doi.org/10.5539/ies.v5n1p216

\begin{abstract}
With transformation of contemporary modern medical educational modes and improvement of requirement upon doctors' humanistic quality, it seems quite important to strengthen humanistic quality-oriented education in medical colleges and universities. Medical humanistic quality-oriented education in China started late, which determines that there are a lot of problems, so it is necessary to refer advanced experiences of foreign countries in terms of course design and teaching methods, etc. to reform medical humanistic quality-oriented education in China.
\end{abstract}

Keywords: Medical colleges and universities, Humanistic quality-oriented, Education

Medical humanistic quality mainly refers to accumulation of medical humanistic knowledge and medical humanistic spiritual cultivation. Specifically speaking, it refers to medical humanistic knowledge that human being should possess and the thought, cultivation, personality and temperament that are particular to the medical humanistic spirit internalized in the body and mind of human being and that are reflected in accumulation of medical humanistic knowledge. Medical humanistic quality structure refers to constitution of basic quality that is developed through cultivation and education on the basis of congenital conditions. Generally speaking, medical humanistic quality structure can be classified into morality quality, which includes ideological quality, political quality and moral quality, cultural and aesthetic quality, which includes cultural quality, and aesthetic quality, health and psychological quality, which includes physiological quality, psychological quality and physical quality, etc. (Guo Yongsong \& Zhang Liangji, 2006)

However, in China, the humanistic quality of medical students currently is still open for further improvement, reflected specifically in the following several aspects (Ma Cungen, 2003). (1) Innovative spirit is relatively not enough. Affected by such factors as low humanistic quality, the overall development of medical students is greatly restrained, especially in the aspects of imagination, development of creativity and expansion of the thinking mode, healthy development and perfection of personality, and interpersonal communication and exchange, where obvious disadvantages exist. (2) Humanistic concern is relatively insufficient. According to a recent research, among the medical complaint cases at present in China, there are quite a large quantity of cases in which doctors have bad attitudes towards patients. Quite a lot of medical students are in confusion about how to deal with the doctor-patient relationship during the clinical probation period, and they rarely have any communication with the patients. (3) Humanistic quality concept is relatively laggard. According to a survey on interns that was conducted by Shanxi Medical University, there were only $58 \%$ interns who thought that humanistic quality-oriented education was indispensable. This proves that quite a lot of medical students have not had enough knowledge in the essence of medical science and in the internal connection between medical science and humanistic courses. (4) Basic humanistic knowledge is relatively deficient. It is not difficult for us to discover among the contemporary medical colleges and universities, quite a lot of medical students have solid professional knowledge, but know little about humanistic science, especially ideological and political theory courses and traditional Chinese cultural, geographical 
and historical knowledge. (5) The utilitarian idea is rooted and the solidarity and cooperative spirit is weak. The reason for learning medicine by a large number of medical students is that the occupation of doctor is stable, with high income, so they are lacking in the ideal of showing concern for patients, dedicating to the society and devoting to the medical treatment and public health career. (6) The spiritual world is void. Under the pressure of single professional courses, medical students are deficient in infiltration and direction of humanistic spirit. Some students even gradually have with them the feeling of loss, lost in confusion about their future. Even when they learn the medical major, they believe in superstition. In the meanwhile, with development of medical science and technology, frontier development and breakthrough of medical science and technology that is represented by human genome project research predicts the forthcoming of a new round of medical revolution. This has brought profound influences upon all fields in a global scope, especially to the field of medical science. Then, transformation of the medical education mode from biomedicine mode to the medical mode of "biology-psychology-society-environment", and the proposal of the concept of five star doctor have brought about new situations and new issues to the ideological education of medical students. Thus, higher medical education has to, first of all, come to have an idea about the status quo of humanistic quality-oriented education among domestic and foreign medical students. (Wu Ping, Wang Chen, Zhang Huan \& el al, 2006)

Western developed countries headed by US attach great importance to medical humanistic education, and their medical humanistic courses have been developed to the maturity. Ever since the earlier Twentieth century, US has proposed setting up courses of non-biomedicine among medical students in higher medical humanistic education, such as, humanities science, sociology and behavioral science, etc. Until the 60s in the Twentieth Century, the above educational idea and proposal had been gradually recognized by people. For development of medical humanistic education, US took the lead in setting up medical humanities and social science courses. By the year 1995, almost all medical colleges in US had set up medical humanities and social science courses, which were rich in content and high in quality. (Zhou Kai, 2010) So far, medical courses in foreign developed countries, especially western countries, are mainly constituted by natural science, humanities and social science and medicine. In these developed countries, it is pointed out that medicine should be mutually integrated with natural science and humanities and social science, namely, a course cluster of humanistic discipline with medicine as the foundation. Medical colleges and universities in foreign developed countries attach great importance to humanistic science and pay attention to establishing an elegant and relaxed humanistic atmosphere, which enables medical students to be edified and affected.

In addition, these countries affect and educate medical students by means of extramural practice, academic culture and consulting service as well as social investigation, etc., so as to make them brought into the process of medical humanistic education. The characteristics of medical humanistic education in medical colleges and universities in foreign developed countries are to strengthen medical humanistic knowledge education, gradually penetrate medical occupational morality content and to bring medical humanistic knowledge into medical treatment practice. The primary purpose is to enable medical students to deepen understanding in survival, death and life meaning of human kind. Thus, it is required that doctors should not only possess proficient medical skill in development, but should also possess extensive medical humanistic knowledge cultivation, not only make perfection more perfect in medical skills, but also serve the patients wholeheartedly in terms of medical ethics. Medical humanistic education should deem self-development of medical students as the starting point and the overall and harmonious development of medical students as the goal, good at discovering personal features and shining points of medical students, and combined together in an organic way with the overall development of medical students. In the process of learning medical humanistic courses, not only students learn knowledge of such subjects as literature, ethics, law and religion and grasp theoretical system of all subjects, but these subjects have unconscious effects on the learning process of medical students, guiding and restraining medical students in their medical practice and enabling medical students to consciously consider problems and resolve problems from different aspects of culture, history, morality, politics, science and medicine, etc. According to education practitioners in western developed countries, the essence of higher medical humanistic education is to regard patients as the center. Medical humanistic education should be closely combined with medical care practice to gradually realize close combination of medical professional courses and medical humanistic courses and gradually realize integration of medical professional courses and medical humanistic courses. (Zhou Guiying, 2008) This is mainly manifested in concentrating on cultivation of practical ability and cultivation of control ability at the time of laying emphasis on theoretical education, and in reflecting throughout the two basic principles of taking patients as the center and closely connecting reality in medical practice. Research on humanistic quality-oriented education in foreign countries has reference significance to medical colleges in China. In summary, humanistic quality-oriented education in foreign countries can be summarized as the following several characteristics. 
In terms of course design: (1) horizontal "relevance". In the process of teaching, humanistic courses should be mutually penetrated with natural science and medical courses, overlapped with each other. For example, lots of medical colleges and universities in foreign countries have set up such medical humanistic courses as medical ethics, medical philosophy, health law, medicine and literature, etc. However, these courses are not taught in isolation, but mutually integrated and closely connected with medical content, such as, the course of "doctor, patient and society" in Medical School of New York University. (2) Longitudinal "sequence". Humanistic courses should be set up at the preclinical stage, but are not finished at the preclinical stage and are extended to the entire process of teaching. For example, in the medical colleges in Japan, students are required to mainly learn courses of basic science and humanistic science within their first two academic years, during which the medical introduction covers medical humanistic courses. In the fifth academic year, students are required to learn continuous medical introduction to have an idea about relations between medical treatment and law, ethics and social economy. The medical courses of the Medical College of Harvard University are also accessible to students in the second academic year and runs through the four academic years. (Rydreh D, 2003) (3) Highlighting applicability. Foreign medical colleges, from beginning to end, run the two basic thoughts of patients as the center and close connection with reality through the process of humanistic course process, attaching great importance to humanistic issues in the contemporary medical field and investigation, survey and analysis as well as resolutions of these issues, and laying great emphasis on integrating humanistic education into medical care practice to realize integration of medical teaching and humanistic course teaching. For example, the special subject of "sociological study on bioscience technology" that is set up the Medical College of Harvard University mainly discusses development of new biological technology and social, ethical and clinical problems faced up by application of the technology. They select relevant data directly from latest published academic journals to compile new textbooks for students to learn and discuss. (Shen Yibin, 2004)

Course teaching method. In order to achieve the purpose of teaching humanistic courses, quite a lot of foreign medical colleges adopt all varieties of teaching methods and means, including classroom teaching, classroom discussion, academic discussion, outside reading, thesis writing and even participation in teaching, etc. They take a case study as the direction, and also extensively adopt the teaching means that takes problems as the basis. As an important teaching method, small group discussion is also greatly favored. Teachers direct students through material reading to encourage students and create opportunities for students to speak out their feelings, information and viewpoints and to give the most sufficient freedom to students. There are also some teachers who conduct activities, such as, specifying teaching materials for students, assigning actual writing training and direct role demonstration. There are also some other teachers who pay special attention to design of teaching context and occasion. For example, they adopt direct discussion means in teaching of medical philosophy and medical ethics, invite doctors and poets, doctors and writers, critical patients, those patients who volunteer to take part in clinical experiment as well as their doctors to discuss together, and even arrange teachers and students to participate in theatre performance together in the plan of teaching, with the aim of putting students really into the context. (Wei Fen, 2004; Cao Kunming, 2009)

Teachership team. In foreign countries, quite a lot of medical colleges have not only obtained support from national humanistic science foundations, but have also aroused focus from philosophers, ethical experts, jurists and economists in some occupational organizations and public institutions. Besides, there are a lot of teachership training institutions to offer teachers for humanistic education. In the teaching of medical humanistic courses, some teachers are not only medical assistants or clinical instructors, but are even medical professors and chief physicians, professors in medical ethics and social medicine, or social workers. All these people have achieved achievements in different disciplines and fields. At present, teachers for medical humanistic education in foreign countries mainly come from the following three sources. In the first place, some humanistic lovers of non-medical professions are invited to work as full-time or part-time teaching and research workers in the medical universities and colleges. In addition, the humanities department which is attached to a comprehensive university also offers important teachers for humanistic education in medical universities and colleges. In the second place, some clinical doctors may learn humanistic subjects after graduation and some have long term particular favor for humanistic teaching. In the third place, among those social workers who take part in teaching, there are a lot of them who are voluntary teachers. For example, US medical universities and colleges invite cancer patients, patients who have received visceral organ transplanting, religionists and social workers to take the task of teaching and even invite painters to hold an art exhibition in the medical colleges and universities and musicians to give a concert in the medical colleges and universities.

The humanistic quality-oriented education in China started in the 80s of the Twentieth Century and was initially development all over the country in the 90s. In 2006, the national medical humanistic quality-oriented education committee was established, and afterwards, medical humanistic education has aroused attention of the education 
circle. However, compared with foreign developed countries, the medical humanistic education in China still has a long way to go. Although a lot of work has been done in medical colleges and universities, and humanistic education has been strengthened, weakness of medical humanistic education is determined due to much professional education content, short length of schooling, heavy learning burden of students and limited time for students to select humanistic courses. In addition to similar humanistic education with regular institutions of higher learning, the condition of courses with overlapping of medicine and humanities is also not optimistic. The courses with overlapping of medicine and humanities (such as, medical ethics, medical psychology, and medical history, etc) have been developed with people's knowledge in medical humanistic education and research on modern medical humanistic subjects, which have gone through the developmental path from being one unit and then popularized and from single subject course and then comprehensive subject courses construction. Major problems existing at present are as following: (Tan Weiping, 2005)(1) In terms of course design, humanities and social science courses are relatively limited, with few class hours, which appropriately accounts for $8 \%$ of the total class hours. (2) combination of teaching content and medical education and practice is lacking. Educational concept relatively lags behind and humanistic courses have not obtained due emphasis. The phenomenon of five emphasis and five ignorance is serious (namely, emphasis on universality and ignorance of individuality, emphasis on utility and ignorance of quality, emphasis of books and ignorance of practice, emphasis on nature and ignorance of humanity, and emphasis on indoctrination and ignorance of internalization). (3) Compared with traditional subject teaching, in terms of teaching arrangement, arrangement of humanistic courses in medical courses is not rigorous, with great randomness. Generally speaking, courses are set up according to what the teachers teach, and are deficient in systematicalness. The course system is lacking in standardization and perfection. Furthermore, humanistic courses in most colleges are not embodied in the teaching plans and some courses even have no teaching syllabus and fixed textbooks. (4) In terms of teaching method, teaching of humanistic courses in medical colleges is mainly inculcation of theories, and lecturing is the primary teaching method. Such teaching methods as heuristic method, discussion method and interactive method have not been effectively applied. (5) The teachership team is still weak. There are quite a large number of subjects that have not had a teaching and research office. Since the medical humanistic education in China medical colleges has not had a long history, and emphasis on humanistic subjects in medical colleges is obviously insufficient, teachers are quite uneven either in the educational background or knowledge structure who are now undertaking humanities and social science teaching. The knowledge structure of teachers is single. (Wang Dijuan \& Wu Peipei, 2007)

Medicine per se contains abundant humanistic spirit, so medical education has to be unified with humanistic quality in order to adapt to the contemporary requirements and enable medical science to better serve the public. According to the status quo of domestic and foreign humanistic quality-oriented education and teaching, features of humanistic quality-oriented education in medical colleges in China, and spirit of relevant documents about humanistic quality-oriented education, much still remains to be done in order to explore the features and rules of medical humanistic quality-oriented education in the Twenty-first century, set up different majors (nursing, clinical medicine and medical test, etc) in medical colleges and work out cultivation modes of humanistic quality-oriented education at different levels (three-year system, five-year education and eight-year system).

\section{References}

Cao, Kunming. (2009). Key to Quality-oriented Education in Colleges and Universities: Integration of Scientific Spirit and Humanistic Spirit. China Adult Education, 6(24):90-91.

Feng, Jiagui. (2005). Exploration on Humanities Education at School. Higher Education Forum, 6(3):56-57.

Guo, Yongsong \& Zhang, Liangji. (2006). Medical Humanistic Education: Problems, Challenges and Countermeasures. Medicine \& Philosophy, 27(12):69-70.

Ma, Cungen. (2003). Status Quo and Enlightenment of Humanities and Social Medical Teaching in North American Higher Medical Colleges and Universities. Medicine and Philosophy, 5(8):54-56.

Rydreh D. (2003). Closing the gap. Funding clinical medical education in Minnesota. Minn Med, 86(2):41-45.

Shen, Yibin. (2004). Medical Humanities Education at New York University School of Medicine. Fudan Education Forum. 6(4):86-87.

Tan, Weiping. (2005). Humanistic Education and Humanistic Course. Hunan People's Publishing House, 45-68.

Wang, Dijuan \& Wu, Peipei. (2007). Combination of Humanities Quality-oriented Education and Medical Education at Medical Colleges and Universities. Northwest Medical Education, 6(1):67-68.

Wei, Fen. (2004). The Medical Humanities: A New Undergraduate Teaching Program at the University of Geneva School of Medicine, Switzerland. Fudan Education Forum, 6(5):90-91. 
Wu, Ping, Wang, Chen \& Zhang, Huan, el al. (2006). Investigation and Reflection on Humanistic Education Condition of Medical Students. China Higher Medical Education, 6(9):123-125.

Zhou, Guiying. (2008). Positioning of the Role of University Teachers in Humanistic Quality-oriented Education. Theoretical Observation, 67-68.

Zhou, Kai. (2010). Value Analysis and Implementation Approach of University Students' Concept of Honor and Disgrace. Education Exploration, 7(5):135-136. 